\title{
Relationship between Angiotensin-Converting Enzyme Insertion/Deletion Gene Polymorphism and Susceptibility of Minimal Change Nephrotic Syndrome: A Meta-Analysis
}

\author{
Tian-Biao Zhou, Yuan-Han Qin, Li-Na Su, Feng-Ying Lei, Wei-Fang Huang, and Yan-Jun Zhao \\ Department of Pediatrics, The First Affiliated Hospital of Guangxi Medical University, Nanning 530021, China \\ Correspondence should be addressed to Tian-Biao Zhou, a126tianbiao@126.com
}

Received 28 December 2010; Revised 23 February 2011; Accepted 8 March 2011

Academic Editor: Alejandro Martín-Malo

Copyright (C) 2011 Tian-Biao Zhou et al. This is an open access article distributed under the Creative Commons Attribution License, which permits unrestricted use, distribution, and reproduction in any medium, provided the original work is properly cited.

\begin{abstract}
Aim. This meta-analysis was performed to evaluate the association between ACE I/D gene polymorphism and MCNS susceptibility. Method. A predefined literature search and selection of eligible relevant studies were performed to collect the data from electronic databases. Results. Six articles were identified for the analysis of association between ACE I/D gene polymorphism and MCNS risk, including 4 for Asians, one in Caucasian population and one for Africans. There was a markedly positive association between $\mathrm{D}$ allele or DD genotype and MCNS susceptibility in Asians (D: $P=.01, \mathrm{DD}: P=.02$ ), but not for Caucasians and Africans (Caucasians: D: $P=.16$, DD: $P=.98$; Africans: D: $P=.81$, DD: $P=.49$ ). Furthermore, the II genotype seemed not to play a protective role against MCNS risk for Asians, Caucasians and Africans $(P=.12, P=.09, P=.76$, resp.). Interestingly, there was also significant association between ACE I/D gene polymorphism and MCNS susceptibility in overall populations (D: $P=.007$, DD: $P=.04$, II: $P=.03)$. Conclusion. D allele or DD genotype might be a significant genetic molecular marker for MCNS susceptibility in Asians and overall populations, but not for Caucasians and Africans. More larger and rigorous genetic epidemiological investigations are required to further explore this association.
\end{abstract}

\section{Introduction}

Minimal change nephrotic syndrome (MCNS) is one of the most important histopathological characteristics in patients with idiopathic nephrotic syndrome (INS), and long-term outcome of most of the patients with this disease is favorable [1]. Some investigations suggested that genetic factors might play a key role in the pathomechanism of MCNS [2-5]. The angiotensin-converting enzyme (ACE) insertion/deletion (I/D) gene polymorphism, correlating with circulating and cellular ACE concentration, might take part in the etiology of MCNS and have been investigated in numerous epidemiologic studies at present. However, the available evidence reported to date is weak, due to sparseness of data or disagreements among studies. There is rare meta-analysis to explore the association of ACE I/D gene polymorphism with MCNS risk. We performed this metaanalysis to investigate the association between ACE I/D gene polymorphism and MCNS susceptibility, with the intention to provide a much more reliable finding on the significance of the association.

\section{Materials and Methods}

2.1. Search Strategy. The relevant studies were screened from the search engines of PubMed, Cochrane Library, and CBMdisc (China Biological Medicine Database) on September 1, 2010. (Minimal change nephrotic syndrome OR MCNS) AND (Angiotensin converting enzyme OR ACE) was used in PubMed, Cochrane Library, and CBM-disc. The search in PubMed was limited to humans. We also extended search spectrum to the "related articles" and the bibliographies of all retrieved studies. If multiple publications from the same study group occurred, we only recruited the most complete paper for analysis. 
TABLE 1: Characteristics of the studies evaluating the effects of ACE genes on MCNS risk.

\begin{tabular}{|c|c|c|c|c|c|c|c|c|c|}
\hline \multirow{2}{*}{ First author, year } & \multirow{2}{*}{ Ethnicity } & \multicolumn{3}{|c|}{ Case } & \multicolumn{3}{|c|}{ Control } & \multicolumn{2}{|c|}{ D allele (\%) } \\
\hline & & DD & ID & II & $\mathrm{DD}$ & ID & II & Case & Control \\
\hline Lee 1997 [8] & Asian & 9 & 25 & 21 & 9 & 25 & 27 & 39.10 & 35.25 \\
\hline Al-Eisa 2001 [9] & Asian & 16 & 5 & 1 & 25 & 22 & 1 & 84.09 & 75.00 \\
\hline Sasongko 2005 [10] & Asian & 4 & 26 & 39 & 6 & 21 & 41 & 24.63 & 24.26 \\
\hline Serdaroglu 2005 [11] & Asian & 36 & 27 & 10 & 99 & 124 & 64 & 67.81 & 56.10 \\
\hline Sasse 2006 [7] & Caucasian & 5 & 12 & 0 & 58 & 91 & 50 & 64.71 & 52.01 \\
\hline Saber-Ayad 2010 [6] & African & 0 & 5 & 0 & 10 & 34 & 6 & 50.00 & 54.00 \\
\hline
\end{tabular}

\subsection{Inclusion and Exclusion Criteria}

2.2.1. Inclusion Criteria. (1) A case-control study, (2) the outcome had to be MCNS, and (3) there had to be at least two comparison groups (MCNS group versus control group).

2.2.2. Exclusion Criteria. (1) Review articles; (2) case reports; (3) articles did not provide the detail genotype data; (4) investigated the association of other genes with MCNS.

2.3. Data Extraction and Synthesis. The following information was extracted from each study independently by at least 2 investigators: first author's surname, year of publication, ethnicity of study population, and the number of cases and controls for ACE genotypes. Frequencies of alleles were calculated for case group and control group, from the corresponding genotype distribution. The results were compared and disagreements were resolved by discussion.

2.4. Statistical Analysis. Available data was entered into Cochrane Review Manager (RevMan, version 5) and analyzed. The pooled statistic was counted using the fixed effects model, but a random effects model was conducted when the $P$ value of heterogeneity test was less than .1. Results were expressed with odds ratios (OR) for dichotomous data, and 95\% confidence intervals $(\mathrm{CI})$ were also calculated. $P<.05$ was required for the overall $\mathrm{OR}$ to be deemed statistically significant. $I^{2}$ was used to test the heterogeneity between the included studies. All descriptive data were expressed as mean $\pm \mathrm{SD}$.

\section{Results}

3.1. Study Characteristics. The search yielded 46 references, 38 in Pubmed, 0 from Cochrane Library and 7 in CBM-disc, and one study [6] was included from the "related articles" and the bibliographies of all retrieved studies. According to the inclusion and exclusion criteria, six studies [6-11] were identified for the meta-analysis of the association between ACE I/D gene polymorphism and MCNS susceptibility in our final review. Four studies [8-11] were conducted in Asians, one investigation [7] for Caucasians and one [6] in Africans. All the studies were published in English. The data of our interest were extracted: first author's surname, year of publication, ethnicity of study population, and the number of cases and controls for ACE genotypes (Table 1). These six studies contained 241 case series and 713 controls. The average distribution frequency of ACE D allele in Asian patients with MCNS was $53.91 \%$, and the frequency in controls was $47.65 \%$. The average distribution of $\mathrm{D}$ allele frequency in Caucasians was $64.71 \%$ in cases and $52.01 \%$ for controls. Furthermore, the average distribution frequency of D allele in Africans with MCNS was 50.00\%, and the frequency in control group was $54.00 \%$. The ratio of cases/controls for average distribution frequency of $\mathrm{D}$ allele in Caucasians was slightly elevated when compared with those in Asians and Africans (Asians: MCNS/control = 1.13; Caucasians: $\mathrm{MCNS} /$ control = 1.24; Africans: $\mathrm{MCNS} /$ control $=0.93)$.

3.2. Association of the ACE I/D Gene Polymorphism with MCNS Risk. In this meta-analysis, we found there was a significant association between D allele or DD genotype and risk of MCNS in overall populations $(P=.007, P=$ .04; Table 2). The fixed effects OR estimated for the MCNS susceptibility was 1.39 in D allele patients when compared with patients carrying I allele (95\% CI: 1.09-1.76), with evidence of between-study heterogeneity $(P=.64$; Table 2$)$. Furthermore, the fixed effect OR estimated for the risk of developing MCNS was 1.46 in DD homozygous patients compared with both other genes combined (95\% CI: 1.012.11 ), for the reason that the $P$ value of heterogeneity test was .45. We also documented there was notable association between the II genotype and the risk of MCNS relative to both other genotypes combined $(\mathrm{OR}=0.65,95 \% \mathrm{CI}: 0.44-$ $0.96, P=.03$, Table 2).

In our study, we found that the average frequency of $D$ allele in control group of Africans was a little elevation when compared with those in Asians and Caucasians (Africans: 54.00\%; Asians: 47.65\%; Caucasians: 52.01\%). True racespecific genetic effects might affect the results of our analysis for the association of ACE I/D gene polymorphism with the onset of MCNS. In order to evaluate the racespecific effect, we divided the population by ethnicity. In Asians, we found that the association of $\mathrm{D}$ allele or DD genotype with MCNS susceptibility was positively significant 
TABLE 2: Meta analysis of the association of ACE I/D gene polymorphism with MCNS risk.

\begin{tabular}{|c|c|c|c|c|c|c|}
\hline Genetic contrasts & Group and subgroups & Studies number & $Q$ test $P$ value & Model & OR (95\% CI) & $P$ \\
\hline \multirow{4}{*}{ D versus I } & Overall & 6 & .64 & Fixed & $1.39(1.09,1.76)$ & .007 \\
\hline & Asian & 4 & .46 & Fixed & $1.38(1.07,1.79)$ & .01 \\
\hline & Caucasian & 1 & - & Fixed & $1.69(0.81,3.51)$ & .16 \\
\hline & Africa & 1 & 一 & Fixed & $0.85(0.23,3.13)$ & .81 \\
\hline \multirow{4}{*}{$\mathrm{DD}$ versus $(\mathrm{DI}+\mathrm{II})$} & Overall & 6 & .45 & Fixed & $1.46(1.01,2.11)$ & .04 \\
\hline & Asian & 4 & .36 & Fixed & $1.60(1.07,2.38)$ & .02 \\
\hline & Caucasian & 1 & - & Fixed & $1.01(0.34,3.00)$ & .98 \\
\hline & Africa & 1 & - & Fixed & $0.35(0.02,6.86)$ & .49 \\
\hline \multirow{4}{*}{ II versus $(\mathrm{DI}+\mathrm{DD})$} & Overall & 6 & .58 & Fixed & $0.65(0.44,0.96)$ & .03 \\
\hline & Asian & 4 & .70 & Fixed & $0.73(0.49,1.09)$ & .12 \\
\hline & Caucasian & 1 & - & Fixed & $0.08(0.00,1.43)$ & .09 \\
\hline & Africa & 1 & - & Fixed & $0.62(0.03,12.62)$ & .76 \\
\hline
\end{tabular}

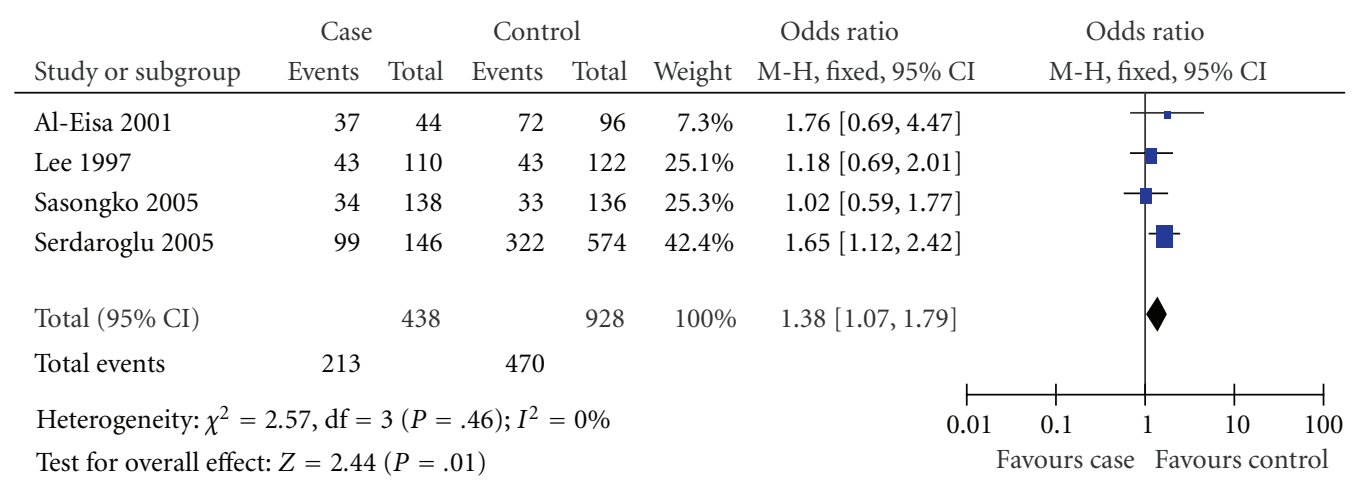

FIgURE 1: Relationship between D allele and MCNS risk in Asians.

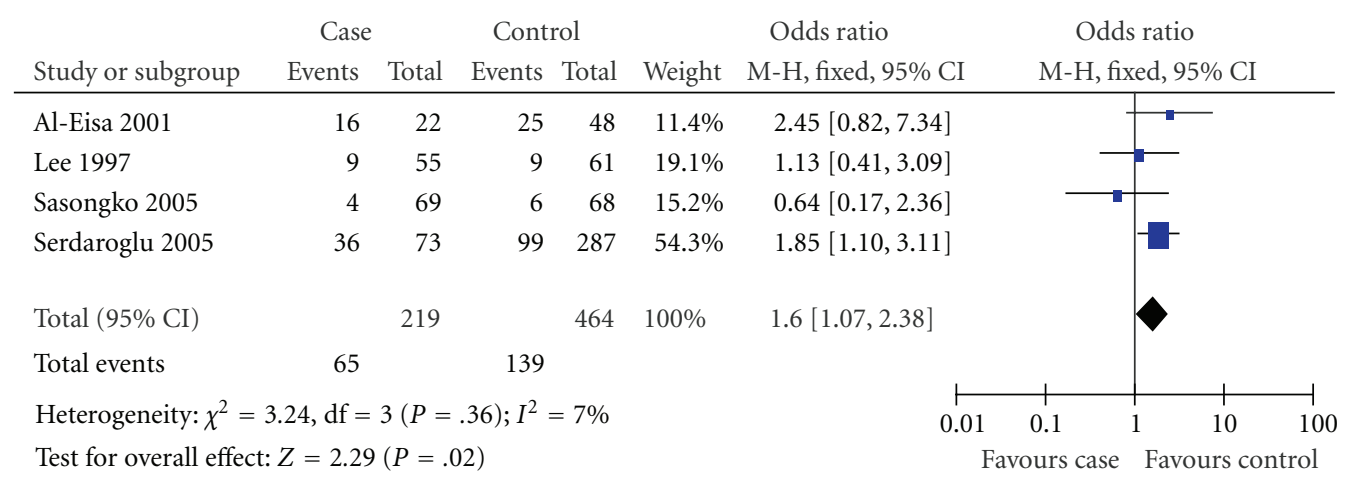

FIgURE 2: Association of DD genotype with MCNS susceptibility in Asians.

$(P=.01$ and $P=.02$, resp.) (Table 2, Figures 1 and 2$)$. However, the II genotype seemed not to play a protective role against MCNS risk for Asians (OR $=0.73,95 \%$ CI: $0.49-1.09 ; P=.12$ ) (Table 2, Figure 3). Interestingly, there was also no significant association between ACE I/D gene polymorphism and MCNS susceptibility in Caucasian population and Africans (Caucasian: D: $P=.16$; DD: $P=$ .98; II: $P=.09$; Africans: D: $P=.81$; DD: $P=.49$; II: $P=.76)$ (Table 2).

\section{Discussion}

There is increasing evidence suggesting that the renninangiotensin system (RAS) has been a well-documented participation in the pathogenesis of renal disease. Genetic markers, in particular ACE I/D gene polymorphism, might offer some benefits to better predict the outcome of renal diseases. The level of plasma ACE, constitutively expressed in several types of somatic cells, is linked to an I/D 


\begin{tabular}{|c|c|c|c|c|c|c|c|}
\hline \multirow[b]{2}{*}{ Study or subgroup } & \multicolumn{2}{|c|}{ Case } & \multicolumn{2}{|c|}{ Control } & \multirow[b]{2}{*}{ Weight } & Odds ratio & \multirow{2}{*}{$\begin{array}{c}\text { Odds ratio } \\
\text { M-H, fixed, 95\% CI }\end{array}$} \\
\hline & Events & Total & Events & Total & & M-H, fixed, 95\% CI & \\
\hline Al-Eisa 2001 & 1 & 22 & 1 & 48 & $1.1 \%$ & $2.24[0.13,37.52]$ & 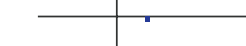 \\
\hline Lee 1997 & 21 & 55 & 27 & 61 & $27.9 \%$ & $0.78[0.37,1.63]$ & \\
\hline Sasongko 2005 & 39 & 69 & 41 & 68 & $31.6 \%$ & $0.86[0.43,1.69]$ & \\
\hline Serdaroglu 2005 & 10 & 73 & 64 & 287 & $39.4 \%$ & $0.55[0.27,1.14]$ & - \\
\hline Total $(95 \% \mathrm{CI})$ & & 219 & & 464 & $100 \%$ & $0.73[0.49,1.09]$ & \\
\hline Total events & 71 & & 133 & & & & \\
\hline Heterogeneity: $\chi^{2}=$ & $41, \mathrm{df}=$ & $3(P=$ & $.7) ; I^{2}=$ & $0 \%$ & & 0.01 & 0.1 \\
\hline
\end{tabular}

FIgURE 3: Association between II homozygous and risk of MCNS in Asians.

gene polymorphism of $287 \mathrm{bp}$ in intron 16 of the ACE gene $[7,12]$. The $\mathrm{D}$ allele and $\mathrm{DD}$ genotype has been reported to be associated with higher plasma ACE level [13]. ACE is a key enzyme of RAS that can convert inactive angiotensin I into a vasoactive and aldosterone-stimulating peptide angiotensin II $[14,15]$. The elevation of ACE protein expression might be responsible for the elevation of plasma angiotensin II level [16]. Increased angiotensin II level makes deleterious actions on renal hemodynamics and induces the protein expression of some other growth factors, leading to glomerulosclerosis [17, 18]. MCNS, an important histopathological characteristic of INS, is one of the most common acquired renal diseases. Data on the risk factors for poor prognosis and the pathogenesis of MCNS are insufficient. Furthermore, findings on the association of ACE I/D gene polymorphism with MCNS susceptibility have been controversial since the first investigation was reported. In order to draw a more convincing conclusion, this meta-analysis was performed to explore the association between ACE I/D gene polymorphism and MCNS risk.

In this investigation, six studies were recruited into our meta-analysis, four studies in Asians, one investigation for Caucasian population and one in Africans. In order to achieve a satisfactory power, meta-analysis of multiple studies clearly has a role in offering an association with such potentials. In our meta-analysis for overall populations, we found the association between D allele or DD homozygous and the risk of MCNS was statistically significant, and the II genotype seemed to play a protective factor against MCNS risk. However, the disequilibrium of gene distributions among Asians, Caucasians, and Africans in healthy controls was observed in our study, which might affect the credibility of the conclusion. The average frequency of $\mathrm{D}$ allele in control group for African population was a little elevation when compared with that in Asians or Caucasians, suggesting a discrepant role of continental differences in gene background and living environment. The results of overall population might be less powerful and it was difficult to draw a convincing conclusion. Therefore, the subgroup analysis was very important in this meta-analysis. In our subgroup analysis, we found that D allele or DD genotype was associated with MCNS susceptibility in Asians, but not for Caucasians and African population. Furthermore, II genotype seemed not to play a positive role against MCNS onset for three races. We speculated that D allele or DD homozygous might sensitively affect MCNS susceptibility in Asians, but not other two races.

In the included investigations, some studies found the ACE I/D gene polymorphism might not be associated with MCNS susceptibility. In Asians, Lee et al. [8] found that the distribution of ACE genotypes in Korean patients with MCNS was similar to that in control, and the DD genotype was more frequent in focal segmental glomerulosclerosis (FSGS) than in MCNS. Sasongko et al. [10] performed an investigation in Javanese-Indonesian patients and found the ACE genotype frequencies of MCNS patients were consistent with those of the controls, and D-allele tended to exist more frequently in FSGS patients than in the MCNS patients and controls. In Caucasians, the similar results were taken place. Sasse et al. [7] found there was no significant correlation between ACE genotype and histology of FSGS or MCNS. Furthermore, in Africans, Saber-Ayad et al. [6] also performed a study on Egyptian children with INS and did not find an association between the ACE I/D gene polymorphism and histological findings (including MCNS and FSGS). The results in those studies mentioned above were consistent with ours for Caucasians and African population, but our conclusions were inconsistent with those of Asians above. However, in the other studies for Asian population, the study of Al-Eisa et al. [9] suggested an association of the D-allele of the ACE gene I/D polymorphism with the clinical manifestation of INS in Kuwaiti Arab children, but they had not calculated the associations of ACE I/D gene polymorphism with MCNS risk between the controls and case group, and Serdaroglu et al. [11] found that D allele frequency was higher in INS group than control group in Turks and the D allele frequency had no statistically significant difference between MCNS group and FSGS group. We speculated that the D allele frequency in MCNS group in the investigation of Serdaroglu et al. might be elevated when compared with that in controls. The sample number of the study from Serdaroglu et al. was much larger than that in other investigations. The conclusion of Serdaroglu et al. might be more stable when compared with that of others. 
Interestingly, in our investigation, we found the distributions of $\mathrm{D}$ allele frequency in control group among four Asian studies were disequilibrium, ranged from $24.26 \%$ to $75.00 \%$. The investigated countries for those studies were from East Asian to West Asian. In the past years, some studies found that living environment might influence the gene expression [19-22]. We speculated that the living environment might affect the $\mathrm{D}$ allele frequency in controls. On the other hand, the sample sizes for some studies were small, which might affect the result for the D allele frequency in controls. In order to draw a more stable conclusion for Asians, some investigations following larger sample sizes are needed in the future.

For Caucasians, The ratio of cases/controls for average distribution frequency of $\mathrm{D}$ allele in Caucasians was 1.24, which is slightly elevated when compared with those in Asians and Africans. However, the ACE I/D gene polymorphism were not associated with the risk of MCNS in Caucasians (the analysis for Caucasians only including one study). More investigations are required to investigate this relationship for Caucasian population in the future. The same as that, more studies investigating the association between ACE I/D gene polymorphism and MCNS susceptibility for African population are required in the future study.

There were some meta-analyses to explore the relationship between ACE I/D gene polymorphism and the susceptibility of some diseases in the past years. Zhang et al. [23] conducted a meta-analysis to investigate the association of ACE I/D gene polymorphism with asthma risk and found there was an association between D allele or DD homozygote and the onset of asthma in Asians but not for Caucasian population. Ji et al. [24] performed a meta-analysis to explore the relation between ACE I/D gene polymorphism and risk of hypertension in Asian population and found that DD genotype was associated with the onset of hypertension. Yong et al. [25] and Schena et al. [26], respectively, took a meta-analysis for the association of ACE I/D gene polymorphism with susceptibility of immunoglobulin A nephropathy (IgAN) and observed that the DD homozygous was associated with an increased risk of IgAN in Asians, but not for Caucasian population. However, there is rarely a meta-analysis for African population at present. The conclusions of our investigation were similar to those in the meta-analyses mentioned above and also found ACE D allele or DD homozygote was more sensitive for Asians when compared with other ethnic groups.

\section{Limitations}

Some limitations should be discussed in this meta-analysis. First, an important threat to any literature-based review and meta-analysis is that of reporting bias (we only searched the published literatures in English or Chinese). Second, the sample sizes in some studies are relatively small. Last but not the least, the genotype distributions of the control population in two included studies $[6,11]$ did not conform to Hardy-Weinberg equilibrium test and it might cause bias in our study. Undoubtedly, the limitations mentioned above might affect our final conclusions.

\section{Conclusions}

In conclusion, the results in our study supported that DD genotype or D allele was associated with MCNS susceptibility in Asians and overall populations, but the association was not found in Caucasians and Africans. The II homozygous seemed to play a protective role against MCNS risk in overall populations, but the associations in Asians, Caucasian population and Africans were not observed. However, more case-control association investigations on larger, stratified populations are required to further clarify the role of this ACE I/D gene polymorphism in MCNS susceptibility.

\section{Conflict of Interests}

The authors declare that they have no conflict of interest.

\section{Acknowledgment}

The authors would like to gratefully acknowledge the most helpful comments on this paper received from professor Liang Rong, Department of Pediatric-Neonatology, Baylor College of Medicine, Houston, TX, USA. T.-B. Zhou and Y.-H. Qin are regarded as joint first authors.

\section{References}

[1] H. A. C. Kyrieleis, M. M. Löwik, I. Pronk et al., "Long-term outcome of biopsy-proven, frequently relapsing minimalchange nephrotic syndrome in children," Clinical Journal of the American Society of Nephrology, vol. 4, no. 10, pp. 1593-1600, 2009.

[2] W. K. Gong, W. Cheung, and H. K. Yap, "Minimal change nephrotic syndrome-a complex genetic disorder," Annals of the Academy of Medicine Singapore, vol. 29, no. 3, pp. 351-356, 2000.

[3] L. Zhang, Y. Dai, W. Peng, J. Lu, Y. Zhang, and L. Wang, "Genome-wwide analysis of histone H3 lysine 4 trimethylation in peripheral blood mononuclear cells of minimal change nephrotic syndrome patients," American Journal of Nephrology, vol. 30, no. 6, pp. 505-513, 2009.

[4] B. Alasehirli, A. Balat, O. Barlas, and A. Kont, "Nitric oxide synthase gene polymorphisms in children with minimal change nephrotic syndrome," Pediatrics International, vol. 51, no. 1, pp. 75-78, 2009.

[5] Y. Ikeuchi, Y. Kobayashi, H. Arakawa, M. Suzuki, K. Tamra, and A. Morikawa, "Polymorphisms in interleukin-4-related genes in patients with minimal change nephrotic syndrome," Pediatric Nephrology, vol. 24, no. 3, pp. 489-495, 2009.

[6] M. Saber-Ayad, S. Sabry, I. Abdel-Latif, H. Nabil, S. A. El-Azm, and S. Abdel-Shafy, "Effect of angiotensin-converting enzyme gene insertion/deletion polymorphism on steroid resistance in Egyptian children with idiopathic nephrotic syndrome," Journal of the Renin-Angiotensin-Aldosterone System, vol. 11, no. 2, pp. 111-118, 2010.

[7] B. Sasse, S. Hailemariam, R. P. Wüthrich, M. J. Kemper, and T. J. Neuhaus, "Angiotensin converting enzyme gene polymorphisms do not predict the course of idiopathic nephrotic syndrome in Swiss children," Nephrology, vol. 11, no. 6 , pp. 538-541, 2006. 
[8] D. Y. Lee, W. Kim, S. K. Kang, G. Y. Koh, and S. K. Park, "Angiotensin-converting enzyme gene polymorphism in patients with minimal-change nephrotic syndrome and focal segmental glomerulosclerosis," Nephron, vol. 77, no. 4, pp. 471-473, 1997.

[9] A. Al-Eisa, M. Z. Haider, and B. S. Srivastva, "Angiotensin converting enzyme gene insertion/deletion polymorphism in idiopathic nephrotic syndrome in Kuwaiti Arab children," Scandinavian Journal of Urology and Nephrology, vol. 35, no. 3, pp. 239-242, 2001.

[10] T. H. Sasongko, A. H. Sadewa, P. A. Kusuma et al., "ACE gene polymorphism in children with nephrotic syndrome in the Indonesian population," The Kobe Journal of Medical Sciences, vol. 51, no. 3-4, pp. 41-47, 2005.

[11] E. Serdaroglu, S. Mir, A. Berdeli, N. Aksu, and M. Bak, "ACE gene insertion/deletion polymorphism in childhood idiopathic nephrotic syndrome," Pediatric Nephrology, vol. 20, no. 12, pp. 1738-1743, 2005.

[12] E. M. Al-Harbi, E. M. Farid, K. A. Gumaa, E. M. Masuadi, and J. Singh, "Angiotensin-converting enzyme gene polymorphisms and T2DM in a case-control association study of the Bahraini population," Molecular and Cellular Biochemistry, vol. 350, no. 1-2, pp. 119-125, 2011.

[13] L. Tiret, B. Rigat, S. Visvikis et al., "Evidence, from combined segregation and linkage analysis, that a variant of the angiotensin I-converting enzyme (ACE) gene controls plasma ACE levels," American Journal of Human Genetics, vol. 51, no. 1, pp. 197-205, 1992.

[14] D. W. Lambert, N. E. Clarke, and A. J. Turner, "Not just angiotensinases: new roles for the angiotensin-converting enzymes," Cellular and Molecular Life Sciences, vol. 67, no. 1, pp. 89-98, 2010.

[15] J. S. Lubel, C. B. Herath, L. M. Burrell, and P. W. Angus, "Liver disease and the renin-angiotensin system: recent discoveries and clinical implications," Journal of Gastroenterology and Hepatology, vol. 23, no. 9, pp. 1327-1338, 2008.

[16] A. Ribeiro-Oliveira, A. I. Nogueira, R. M. Pereira, W. W. Vilas Boas, R. A. Souza dos Santos, and A. C. Simões e Silva, "The renin-angiotensin system and diabetes: an update," Vascular Health and Risk Management, vol. 4, no. 4, pp. 787-803, 2008.

[17] Y. Kaneshiro, A. Ichihara, M. Sakoda et al., "Slowly progressive, angiotensin II-independent glomerulosclerosis in human (pro)renin receptor-transgenic rats," Journal of the American Society of Nephrology, vol. 18, no. 6, pp. 1789-1795, 2007.

[18] A. C. Huby, M. P. Rastaldi, K. Caron, O. Smithies, J. C. Dussaule, and C. Chatziantoniou, "Restoration of podocyte structure and improvement of chronic renal disease in transgenic mice overexpressing renin," PLoS ONE, vol. 4, no. 8, article e6721, 2009.

[19] I. Reiner and G. Spangler, "Dopamine D4 receptor exon III polymorphism, adverse life events and personality traits in a nonclinical german adult sample," Neuropsychobiology, vol. 63, no. 1, pp. 52-58, 2010.

[20] J. D. Coplan, C. G. Abdallah, J. Kaufman et al., "Earlylife stress, corticotropin-releasing factor, and serotonin transporter gene: a pilot study," Psychoneuroendocrinology, vol. 36, no. 2, pp. 289-293, 2011.

[21] C. Yang, Y. Xu, N. Sun et al., "The combined effects of the BDNF and GSK3B genes modulate the relationship between negative life events and major depressive disorder," Brain Research, vol. 1355, pp. 1-6, 2010.
[22] S. Xu, W. Ren, X. Zhou, K. Zhou, and G. Yang, "Sequence polymorphism and geographical variation at a positively selected MHC-DRB gene in the finless porpoise (Neophocaena phocaenoides): implication for recent differentiation of the Yangtze Finless porpoise?" Journal of Molecular Evolution, vol. 71, no. 1, pp. 6-22, 2010.

[23] Y.-G. Zhang, X.-B. Li, J. Zhang et al., “The I/D polymorphism of angiotensin-converting enzyme gene and asthma risk: a meta-analysis," Allergy, vol. 66, no. 2, pp. 197-205, 2011.

[24] L. D. Ji, L. N. Zhang, P. Shen et al., "Association of angiotensinogen gene M235T and angiotensin-converting enzyme gene I/D polymorphisms with essential hypertension in Han Chinese population: a meta-analysis," Journal of Hypertension, vol. 28, no. 3, pp. 419-428, 2010.

[25] D. Yong, W. Q. Qing, L. Hua et al., "Association of angiotensin I-converting enzyme gene insertion/deletion polymorphism and IgA nephropathy: a meta-analysis," American Journal of Nephrology, vol. 26, no. 5, pp. 511-518, 2006.

[26] F. P. Schena, C. D’Altri, G. Cerullo, C. Manno, and L. Gesualdo, "ACE gene polymorphism and IgA nephropathy: an ethnically homogeneous study and a meta-analysis," Kidney International, vol. 60, no. 2, pp. 732-740, 2001. 


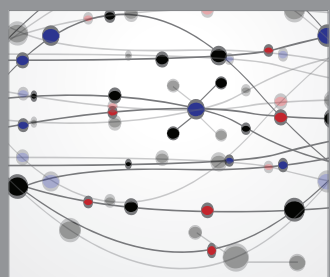

The Scientific World Journal
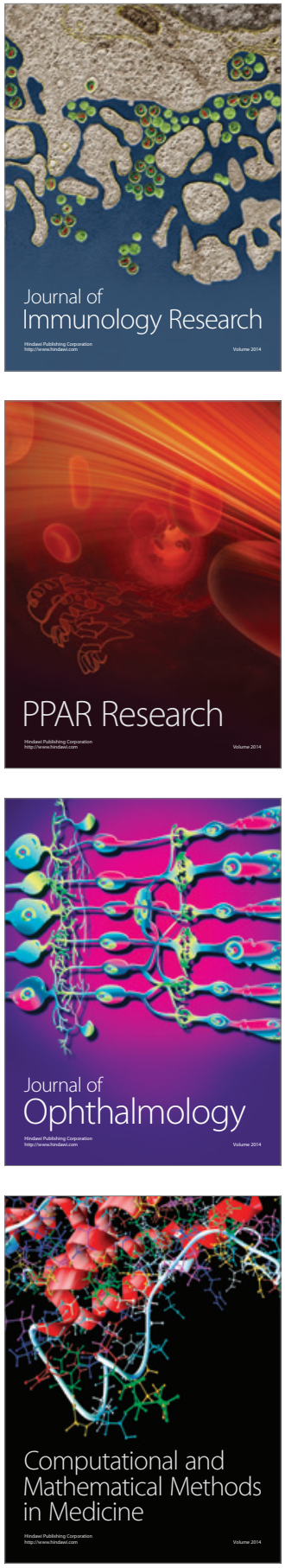

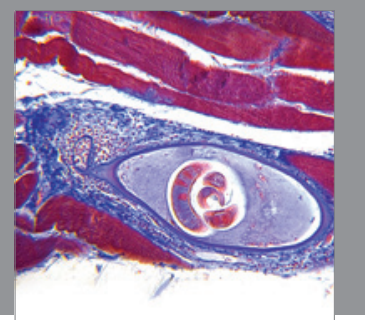

Gastroenterology

Research and Practice
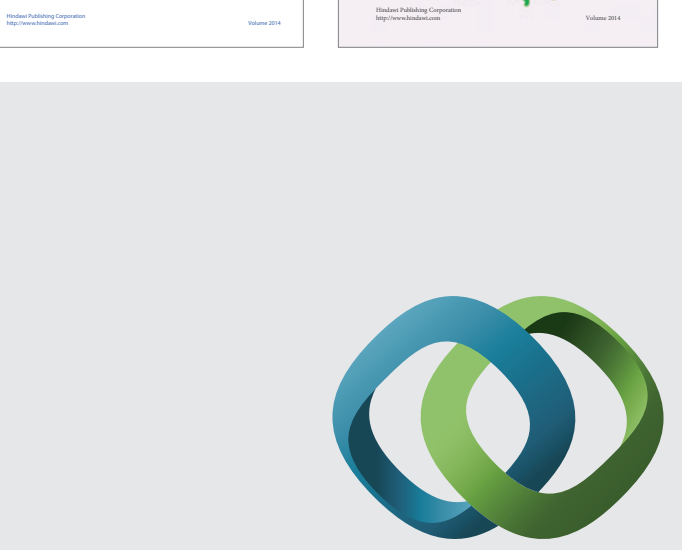

\section{Hindawi}

Submit your manuscripts at

http://www.hindawi.com
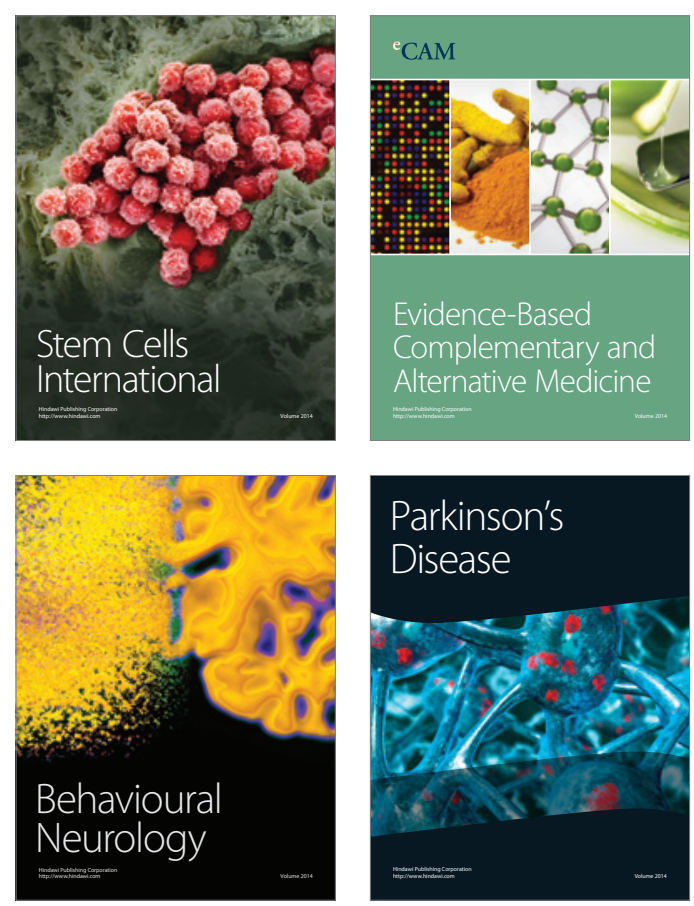

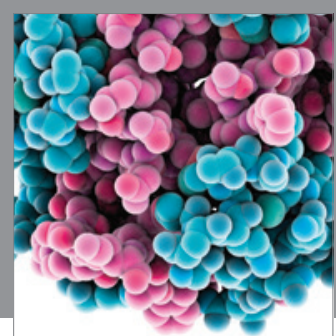

Journal of
Diabetes Research

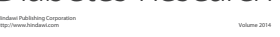

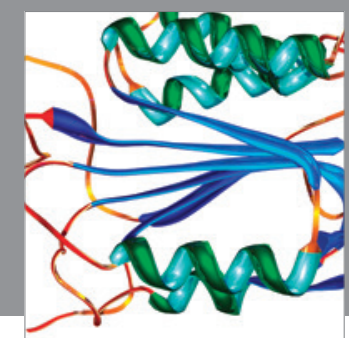

Disease Markers
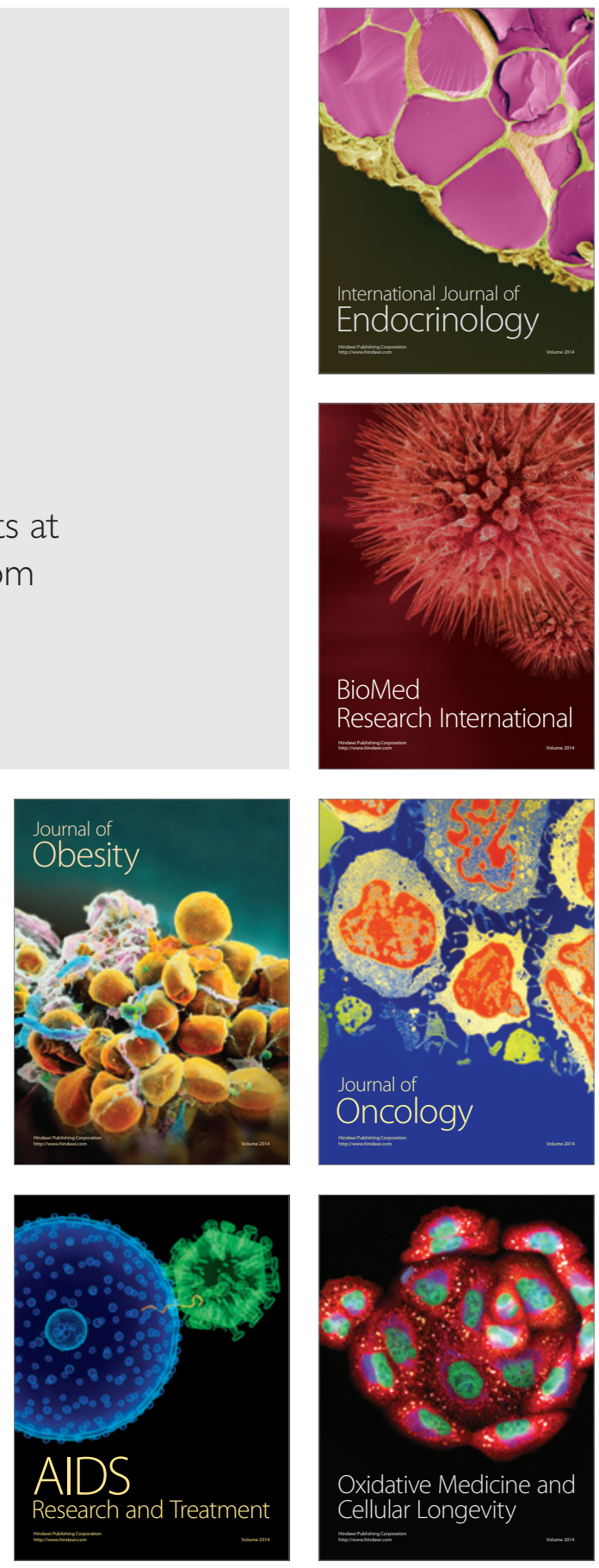